\title{
A SMALL-SCALE DSGE MODEL FOR FORECASTING THE SOUTH AFRICAN ECONOMY
}

GUANGLING (DAVE) LIU AND RANGAN GUPTA

\begin{abstract}
This paper uses aversion of Hansen's (1985) Dynamic Stochastic General Equilibrium (DSGE) model to forecast the South African economy. The calibrated model, based on annual data over the period of 1970-2000, is used to generate one- to eight-quarters-ahead out-of-sample forecast errors for the period of 2001:1 to 2005:4. The forecast errors are then compared with the unrestricted versions of the Classical and Bayesian VARs. A Bayesian VAR with relatively loose priors outperforms both the classical VAR and the DSGE model.
\end{abstract}

Keywords: DSGE Model; VAR and BVAR Model; Forecast Accuracy; DSGE Forecasts; VAR Forecasts; BVAR Forecasts

\section{INTRODUCTION}

This paper develops a small-scale Real Business Cycle Dynamic Stochastic General Equilibrium (DSGE) model for the South African economy, and forecasts real Gross National Product (GNP), consumption, investment, employment, and a measure of the short-term interest rate (91 days Treasury Bill rate), over the period of 1970Q1-2000Q4. The out-of-sample forecasts from the DSGE model is then compared with the forecasts based on an unrestricted vector autoregressive (VAR) and Bayesian VAR (BVAR) models for the period 2001Q1-2005Q4.

Generally, economy-wide forecasting models, at business cycle frequencies, are in the form of simultaneous-equations structural models. However, two problems often encountered with such models are as follows: (i) the correct number of variables needs to be excluded, for proper identification of individual equations in the system which are, however, often based on little theoretical justification (Cooley and LeRoy, 1985); and (ii) given that projected future values are required for the exogenous variables in the system, structural models are poorly suited to forecasting.

The Vector Autoregressive (VAR) model, though 'atheoretical' is particularly useful for forecasting purposes. Moreover, as shown by Zellner (1979) and Zellner and Palm (1974) any structural linear model can be expressed as a VAR moving average (VARMA) model, with the coefficients of the VARMA model being combinations of the structural coefficients. Under certain conditions, a VARMA model can be expressed as a VAR and a VMA model. Thus, a VAR model can be visualized as an approximation of the reduced-form simultaneous equation structural model. 
Though, both the large-scale econometric models and the VARs perform reasonably well as long as there are no structural changes experienced in the economy, they are rendered inappropriate the moment we have structural changes whether in or out of the sample. (Lucas, 1976). Specifically, Lucas (1976) indicated that estimated functional forms obtained for macroeconomic models in the Keynesian tradition, as well as VARs, are not "deep" because these models do not correctly account for the dependence of private agents' behavior on anticipated government policy rules, used for generating current and future values for government policy variables. Under such circumstances, while such models may be useful for forecasting future states of the economy conditional on a given government policy rule, they are fatally flawed when there are changes to government policy rules. Econometrically, this means that in a later time period, $\mathrm{t}+\mathrm{T}$, this problem would show up as an occurrence of a "structural break" in the estimate for the parameters of the model at time $t$. In other words, if the sampling period were broken up into two subsamples, one spanning periods prior to t, and one spanning periods after $t$, it would be seen that the "best-fit" estimates for the parameters of the model, over these two subsamples, are statistically different from each other. $^{1}$

Furthermore, the standard econometric models, as well as the VARs, are linear and hence fail to take account of the nonlinearities in the economy. One and perhaps the best response to these objections has been the development of micro-founded DSGE models that are capable of handling both the possibilities of structural changes and the issues of nonlinearities, since DSGE models are able to identify that the actions of rational agents are not only dependant on government policy variables, but also on government policy rules.

Since Kydland and Prescott (1982), a vast literature has evolved attempting to model the business cycle, as an equilibrium outcome of the representative agents' response to a productivity shock (Hansen, 1985; Hansen and Sargent, 1988; Christiano and Eichenbaum, 1992; King et al., 1988). ${ }^{2}$ Hansen and Prescott (1993) suggest the 1990-91 recession in the U.S. economy can be explained by a real business cycle model with technology shocks. However, the weakness of their analysis, with regard to forecasting, is that it cannot actually forecast the recession since the measurements of technology shocks are ex post. Ingram and Whiteman (1994) show that forecasting with BVAR models, in which priors are generated by real business cycle models, outperforms the one based on standard VAR models. Recently, based on the work done by Christiano, Eichenbaum and Evans (2003), Smets and Wouters (2003a, b) develop micro-founded DSGE models with sticky prices and wages for the U.S. economy. By employing the Baysian techniques, the authors investigate the relative importance of the various frictions and shocks in explaining the U.S. business cycle as well as its prediction performance. They find that the estimated DSGE model is able to outperform the unrestricted VAR and BVAR models in out-of-sample predictions. This result clearly suggests that the micro-founded DSGE models can be used as forecasting tools by central banks.

\footnotetext{
${ }^{1}$ Even though we do not explicitly incorporate the role of government policy, in the DSGE model, but given that the model is microfounded, the set-up would have been immune to the "Lucas Critique", if a government policy was in fact present. See section 2 for further details.

${ }^{2}$ For an exceptional source of research along this line, see Journal of Monetary Economics, 1988, vol. 21 (March/May).
} 
Besides the introduction and conclusion, the paper is organized as follows: section 2 lays out the theoretical model, while section 3 presents the calibration of the model economy. Section 4 discusses the performance of the DSGE model in terms of explaining the business cycle properties of the South African economy and evaluating the accuracy of forecasts relative to the VARs.

\section{THE MODEL ECONOMY}

The model economy, here, is based on the benchmark real business cycle model developed by Hansen (1985). Equilibrium models have been criticized for depending heavily on individuals' substitution of leisure and work responding to the change in interest rate or wage. Hansen (1985) argues that in the real economy labour is indivisible. Individuals either work full time or not at all. Other features of Hansen's indivisible labour are exactly the same as the standard real business model, such as Kydland and Prescott (1982). The economic environment is described below.

The model economy is populated by infinitely-lived households. The preferences of households are assumed to be identical. Households maximize the expected utility over life time:

$U\left(C_{t}, N_{t}\right)=E_{t} \sum_{t=0}^{\infty} \beta^{t}\left(\frac{C_{t}^{1-\eta}-1}{1-\eta}-A N_{t}\right), \quad 0<\beta<1 \quad \eta>0$

where $C_{t}$ and $N_{t}$ are consumption and labour respectively, $\beta$ is the discount factor that households apply to future consumption, and $\eta$ is the coefficient of relative risk aversion. The technology is defined as a standard Cobb-Douglas production function:

$Y_{t}=Z_{t} K_{t-1}^{\rho} N_{t}^{1-\rho}$

where $\rho$ is the fraction of aggregate output that goes to the capital input and $1-\rho$ is the fraction that goes to the labour input. $Z_{t}$ is total factor productivity (TFP) which is exogenously evolving according to the law of motion:

$\log Z_{t}=(1-\psi) \log \bar{Z}+\psi \log Z_{t-1}+\varepsilon_{t}, \quad \varepsilon_{t} \sim$ i.i.d. $\left(0, \sigma^{2}\right)$

where $\psi$ and $\bar{Z}$ are parameters, and $0<\psi<1$.

As in a neoclassical growth model, capital stock depreciates at the rate $\delta$, and households invest a fraction of income in capital stock in each period. This amount of investment forms part of productive capital in the current period. Therefore the law of motion for aggregate capital stock is

$K_{t}=(1-\delta) K_{t-1}+I_{t}, \quad 0<\delta<1$

Although in this indivisible model households do not choose hours worked in competitive equilibrium, the objective of the benevolent social planner is also to maximize the utility of the households (1), subject to the aggregate resource constraints

$Y_{t}=C_{t}+I_{t}$ 
$Y_{f}=Z_{f} K_{f-1}^{\rho} N_{t}^{1-\rho}$

$K_{t}=(1-\delta) K_{t-1}+I_{t}$

$\log Z_{t}=(1-\psi) \log \bar{Z}+\psi \log Z_{t-1}+\varepsilon_{t}, \quad \varepsilon_{t} \sim$ i.i.d. $\left(0, \sigma^{2}\right)$

Uhlig (1995) illustrates the numerical solution methods for solving nonlinear stochastic dynamic models. The following section describes how to calibrate the model economy. Once all the parameters have been assigned, we can then log-linearize the DSGE model ${ }^{3}$ and numerically solve the dynamic problems by employing the method of undetermined coefficients.

\section{CALIBRATION}

This section follows the three-step process as outlined in Cooley and Prescott (1995). This involves moving from the general framework described in the previous section to quantitative measurements of the variables of interest - output, employment, investment, and so on. The first step is restricting the model to display balanced growth, that is, in steady state capital, consumption and investment all grow at a constant rate. The second step is defining the consistent measurements of the conceptual framework of the model economy and the real data. The parameter values of the model economy are then assigned according to the measured data during the sample period of 1970 to 2000.

The annual aggregate capital depreciation rate $\delta$ is obtained from annual averaged values of $\frac{I}{Y}$ and $\frac{K}{Y}$. This yields an annual depreciation rate of 0.076 , or a quarterly rate of 0.019 .

The standard real business cycle literature suggests that capital and labour shares of output have been approximately constant. The capital output share $(\rho)$ is equal to $0.26,{ }^{4}$ obtained from the steady state equation, whereas the labour output share $(1-\rho)$ is 0.74 .

The measurement of technology shock, also known as Solow residual in growth accounting literature (Solow, 1957), is computed as follows:

$\log Z_{t}-\log Z_{t-1}=\left(\log Y_{t}-\log Y_{t-1}\right)-(1-\rho)\left(\log N_{t}-\log N_{t-1}\right)$

Omitting the capital part of the expression ${ }^{5}$ is not a serious problem given the fact that capital stock has very little contribution to the cyclical fluctuations of output (Kydland and Prescott, 1982; Backus, et al., 1995).

The parameter $\bar{Z}$, in the law of motion for TFP (3), is set equal to one. Therefore (3) becomes a first-order linear Markov process:

$\log Z_{t}=\psi \log Z_{t-1}+\varepsilon_{t}, \quad \varepsilon_{t} \sim$ i.i.d. $\left(0, \sigma^{2}\right)$

\footnotetext{
${ }^{3}$ The log-linearized equilibrium conditions are presented in Appendix A.

${ }^{4}$ The capital output share for the South African economy is 0.39 in Zimmermann (2001), and 0.31 in Smit and Burrows (2002).

' There is no quarterly capital stock data available.
} 
Table 1. Parameters calibrated to the model economy

\begin{tabular}{lllllllll}
\hline $\boldsymbol{\rho}$ & $\mathbf{1}-\boldsymbol{\rho}$ & $\mathbf{A}$ & $\overline{\mathbf{Z}}$ & $\boldsymbol{\sigma}$ & $\boldsymbol{\delta}$ & $\boldsymbol{\beta}$ & $\boldsymbol{\psi}$ & $\boldsymbol{\eta}$ \\
0.26 & 0.74 & 2.6712 & 1.00 & 0.0083 & 0.019 & 0.99 & 0.95 & 1.00 \\
\hline
\end{tabular}

Table 2. Statistical moments: Baseline model and RSA data

\begin{tabular}{lclllll}
\hline Variable & \multicolumn{2}{l}{ Baseline Model } & & RSA data & & \\
& SD $(\%)$ & Ratio of SD to that of GNP & Corr. & SD $(\%)$ & Ratio of SD to that of GNP & Corr. \\
GNP & 2.18 & 1.00 & 1.00 & 0.93 & 1.00 & 1.00 \\
CON & 0.63 & 0.29 & 0.87 & 0.80 & 0.86 & 0.44 \\
INV & 10.11 & 4.64 & 0.99 & 4.49 & 4.85 & 0.65 \\
EMP & 1.66 & 0.76 & 0.98 & 0.69 & 0.74 & 0.45 \\
TBILL & 0.06 & 0.03 & 0.95 & 2.36 & 2.55 & 0.00 \\
\hline
\end{tabular}

Notes: Statistics are based on Hodrick-Prescott-filtered data.

The persistence parameter $\psi$ is set equal to 0.95 , which is consistent with the literature (Hansen, 1985). From (10) we can compute a set of innovations of technology $\mathcal{E}_{t}$. These innovations have a standard deviation of $0.0083-$

The discount factor $\beta$ is set equal to 0.99 , as in Hansen (1985), which implies an annual real interest rate of four per cent in steady state. The coefficient of relative risk aversion $\eta$, is set equal to one. The parameter $A$, in the utility function (1), is equal to 2.6712, obtained from (20). As shown in Table 1, all parameters of the model have now been assigned.

\section{EMPIRICAL PERFORMANCE OF THE MODEL}

\subsection{Data moments and cross-correlation}

In this section, we compare the stylized facts of the actual data to those obtained from the baseline model. Table 2 reports a number of statistics for both the baseline model and the actual data. All data are obtained from the South African Reserve Bank Quarterly Bulletins except employment and population (aged 15-64) — obtained from the World Bank database.

The standard deviation of GNP is $21.8 \%$ in the baseline model, but $0.93 \%$ in the actual data. In other words, the baseline model exaggerates the variability of output. So does investment (10.11\% vs. 4.49\%)- Moreover, the baseline model underestimates the variability of the short term interest rate ${ }^{6}(0.06 \%$ vs. $2.36 \%)$. But, in general, the baseline model mimics most of the stylized facts of the business cycle. Employment is more or less as volatile as output $(0.76 \%$ vs. $0.74 \%)$, while investment is much more volatile than output $(4.46 \%$ vs. $4.85 \%)$. Consumption is less volatile than output (0.29\% vs. $0.86 \%)$. In order to be consistent with the model, in which the durability is disregarded, we use the measurement of nondurable goods consumption here. The measurement of consumption, elsewhere in this paper, is total consumption. Total consumption is more variable relative to output (1.07\%) in actual data. ${ }^{7}$ This scenario differs from the empirical regularity. For instance, Backus et al., (1995) show that output is more than 2-3 times variable relative to consumption in the economies of Canada, Japan, United Kingdom,

${ }^{6}$ The short term interest rate, $R$, in actual data is 91 days Treasury Bill rate, a risk-free bank rate, which is comparable with the interest rate in the baseline model.

7 The standard deviation of total consumption is $0.99 \%$, slightly greater than that of output, $0.93 \%$. It results the ratio of standard deviation to that of output, $1.07 \%$. 


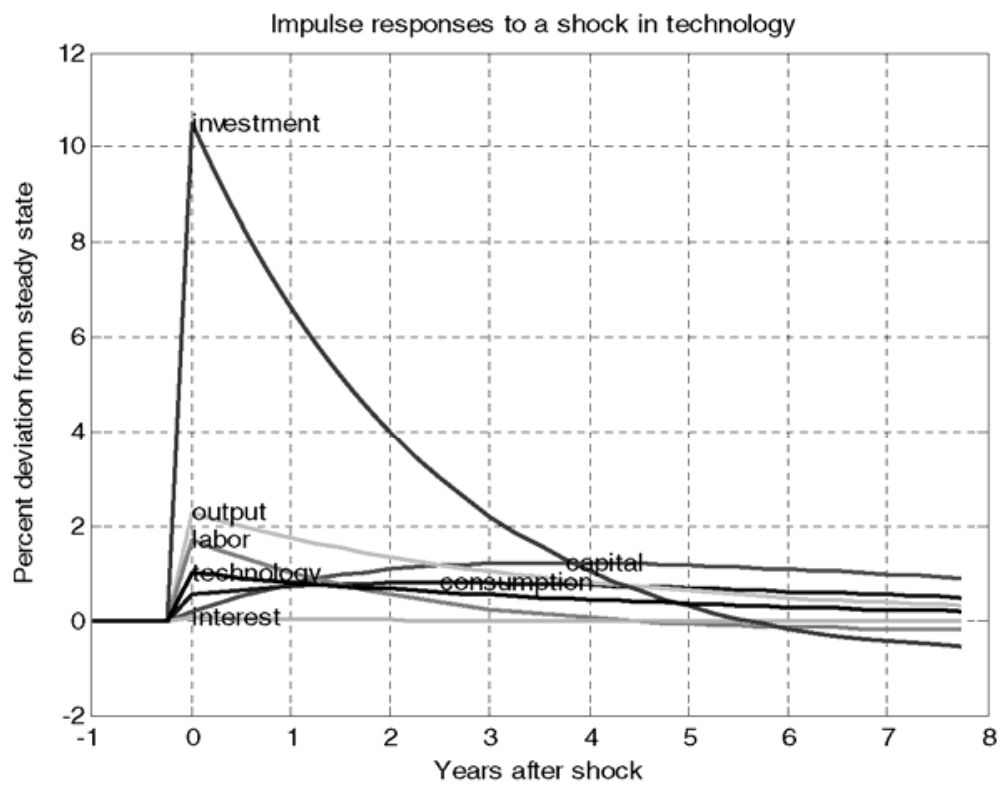

Figure 1. Impulse responses to technology shock (baseline model)

and United States. It indicates that the South African economy has a more volatile total consumption than other economies in general.

In the baseline model, consumption, investment, and employment are highly pro-cyclical, compared to those in actual data. Interest rate also has a high correlation with output, 95\%, whereas there is no correlation between the short term interest rate and output in the actual data.

\subsection{Impulse response analysis}

This section analyzes the responses of aggregate variables with respect to the productivity shock. As shown in Figure 1, the aggregates follow a hump-shaped pattern in response to the shock. In other words, the productivity shock has a transitory output effect, which dies out over time. The response of short term interest rate is minimal, while investment responds the most among the five aggregates. In fact, investment increases more than $10 \%$ in the period that the positive shock occurs.

The scenarios in the actual data are more complicated. Figure 2 shows there is no significant hump-shaped pattern associated with the shock. The short term interest rate also responds little to the shock. The peak effect occurs with a longer lag than that in the baseline model. For instance, the peak effect occurs in the second period after the shock on consumption, third period on investment, and fourth period on labour time. ${ }^{8}$ However, in the baseline model, the peak effect on all aggregates happens in the same period when the shock occurs. Investment does not exhibit the most response to the shock. Instead, the shock has a negative effect in the first period after the shock and a positive effect in the second period, then negative effect again from the third period

\footnotetext{
${ }^{8}$ In order to compare with the baseline model, we generate labor time by dividing employment with population aged 15-64 \{NIL in Figure 2).
} 


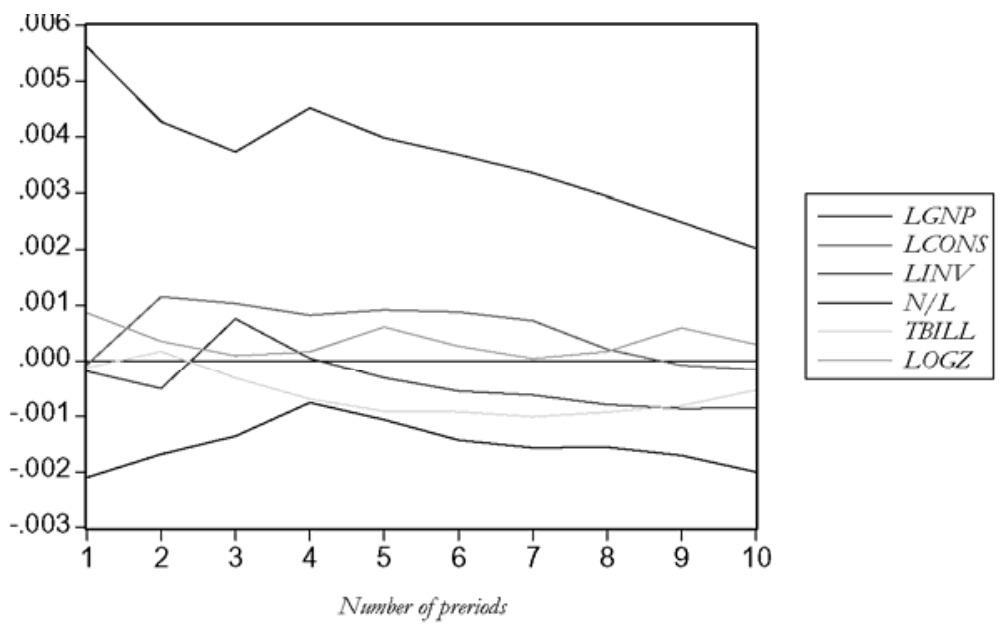

Figure 2. Impulse responses to technology shock (actual data)

onwards. The most serious problem is labour time, which exhibits a negative response to the shock.

\subsection{Forecast accuracy}

In this section, we compare the out-of-sample forecasting performance of the DSGE model with the VARs, both Classical and Bayesian, in terms of the Mean Absolute Percentage Errors (MAPEs). ${ }^{9}$ Before this, however, it is important to lay out the basic structural difference and, hence, the advantages of using Bayesian VARs (BVARs) over traditional VARs, for forecasting.

4.3.1 Classical and BayesianVARs An unrestricted VAR model, as suggested by Sims (1980), can be written as follows:

$\chi_{t}=C+\lambda(L) \chi_{t}+\varepsilon_{t}$

where $\chi$ is a ( $n \mathrm{X} 1$ ) vector of variables being forecasted; $\lambda(L)$ is a ( $n \mathrm{X} n$ ) polynominal matrix in the backshift operator $L$ with lag lenth $p$, i.e., $\lambda(L)=\lambda_{1} L+\lambda_{2} L^{2}+\ldots+\lambda_{p} L^{p}$; $C$ is a ( $n X 1)$ vector of constant terms; and $\varepsilon$ is a ( $n X 1)$ vector of white-noise error terms.

${ }^{9}$ Whitley (1994:187) argues that although the forecast accuracy can be evaluated by the comparison of MAPEs from different forecast models, there is no absolute measure of forecast performance against which to judge them.

MAPE $=\left[\frac{1}{n} \sum_{t=1}^{n} \frac{\left|F_{t}-\hat{F}_{t}\right|}{F_{t}}\right] \times 100$, where $n$ is the number of observations, $F_{t}$ is the actual value of

the specific variable for period $t$ and $\hat{F}_{t}$ is the forecast value for period $t$. The summation is calculated as the following: for one period ahead forecast MAPE, the summation runs from 2001Q1 to 2005Q4; for two period ahead forecast MAPE, it runs from 2001Q2 to 2005Q4; and so on. 
The VAR model, thus, posits a set of relationships between the past lagged values of all variables and the current value of each variable in the model.

A crucial drawback of the VAR forecasts is "overfitting" due to the inclusion of too many lags and too many variables, some of which may be insignificant. The problem of "overfitting", resulting in multicollinearity and a loss of degrees of freedom, leads to inefficient estimates and large out-of-sample forecasting errors. Thus, it can be argued that the performance of VAR forecasts will deteriorate rapidly as the forecasting horizon becomes longer.

A forecaster can overcome this "overfitting" problem by using Bayesian techniques. The Bayesian model proposed by Litterman (1981), Doan et al. (1984), and Litterman (1986), imposes restrictions on those coefficients by assuming they are more likely to be near zero. The restrictions are imposed by specifying normal prior ${ }^{10}$ distributions with zero means and small standard deviations for all the coefficients with standard deviations decreasing as lags increase. One exception is that the mean of the first own lag of a variable is set equal to unity to reflect the assumption that own lags account for most of the variation of the given variable. To illustrate the Bayesian technique, suppose the "Minnesota prior" means and variances take the following form:

$\beta_{i} \sim N\left(1, \sigma_{\beta_{i}}^{2}\right)$

$\beta_{j} \sim N\left(0, \sigma_{\beta_{j}}^{2}\right)$

where $\beta_{i}$ represents the coefficients associated with the lagged dependent variables in each equation of the VAR, while $\beta_{i}$ represents coefficients other than $\beta_{i}$. The prior variances, $\sigma_{\beta_{i}}^{2}$ and $\sigma_{B_{i}}^{2}$, specify the uncertainty of the prior means, $\beta_{i}=1$ and $\beta_{j}=0$, respectively. Doan et al. (1984) propose a formula to generate standard deviations as a function of a small number of hyperparameters: ${ }^{11} w, d$, and a weighting matrix $f\{i, j)$. This approach allows the forecaster to specify individual prior variances for a large number of coefficients based on only a few hyperparameters. The specification of the standard deviation of the distribution of the prior imposed on variable $j$ in equation? $i$ at lag $m$, for all $i, j$ and $m$, defined as $S\{i, j, m)$ :

$$
S(i, j, m)=[w \times g(m) \times f(i, j)] \frac{\hat{\sigma}_{i}}{\hat{\sigma}_{j}}
$$

where:

$$
\begin{aligned}
& f(i, j)= \begin{cases}1 & \text { if } i=j \\
k_{i j} & \text { otherwise, } 0 \leq k_{i j} \leq 1\end{cases} \\
& g(m)=m^{-d}, \quad d>0
\end{aligned}
$$

${ }^{10}$ Note Litterman (1981) uses a diffuse prior for the constant, which is popularly referred to as the "Minnesota prior" due to its development at the University of Minnesota and the Federal Reserve bank at Minneapolis.

1 The name of hyperparameter is to distinguish it from the estimated coefficients, the parameters of the model itself. 
Table 3. MAPE(2001:1-2005:4): Real GNP in logs

\begin{tabular}{|c|c|c|c|c|c|c|c|}
\hline \multirow[t]{2}{*}{$\overline{\mathrm{QA}}$} & \multirow[t]{2}{*}{ VAR } & \multirow[t]{2}{*}{ DSGE } & \multicolumn{5}{|l|}{ BVARs } \\
\hline & & & $(\mathrm{w}=0.3, \mathrm{~d}=0.5)$ & $(\mathrm{w}=0.2, \mathrm{~d}=1)$ & $(\mathrm{w}=0.2, \mathrm{~d}=2)$ & $(\mathrm{w}=0.1, \mathrm{~d}=1)$ & $(\mathrm{w}=0.1, \mathrm{~d}=2)$ \\
\hline 1 & 0.0000 & 7.2790 & 0.00001 & 0.00004 & 0.00041 & 0.00013 & 0.00062 \\
\hline 2 & 0.0039 & 7.2678 & 0.00394 & 0.00404 & 0.00483 & 0.00429 & 0.00527 \\
\hline 3 & 0.0067 & 6.8978 & 0.00670 & 0.00688 & 0.00794 & 0.00724 & 0.00822 \\
\hline 4 & 0.0020 & 7.2569 & 0.00205 & 0.00227 & 0.00359 & 0.00275 & 0.00400 \\
\hline 5 & 0.0026 & 7.2468 & 0.00259 & 0.00231 & 0.00072 & 0.00173 & 0.00026 \\
\hline 6 & 0.0006 & 7.2267 & 0.00059 & 0.00032 & 0.00132 & 0.00026 & 0.00178 \\
\hline 7 & 0.0061 & 7.2110 & 0.00605 & 0.00575 & 0.00404 & 0.00514 & 0.00359 \\
\hline 8 & 0.0048 & 7.1908 & 0.00477 & 0.00447 & 0.00268 & 0.00384 & 0.00219 \\
\hline AVE & 0.0033 & 7.1971 & 0.00334 & 0.00326 & 0.00319 & 0.00317 & 0.00324 \\
\hline
\end{tabular}

MAPE: mean absolute percentage error; QA: quarter ahead.

The term $w$ is the measurement of the standard deviation on the first own lag, which indicates the overall tightness. A decrease in the value of $w$ results in a tighter prior. The parameter $g(m)$ measures the tightness on lag $m$ relative to lag 1 , and is assumed to have a harmonic shape with a decay of $d$. An increasing $d$ tightens the prior as the lag increases. The parameter $f(i, j)$ represents the tightness of variable in $j$ equation relative $i$ ? to variable

$i$. Reducing the interaction parameter $k_{i j}$ tightens the prior. $\hat{\sigma}_{\text {: }}$ and $\hat{\sigma}_{i}$ are the estimated standard errors of the univariate autoregression for variable $i$ and $y$ respectively. In the case of $i \neq j$, the standard deviations of the coefficients on lags are not scale invariant

(Litterman, 1986:30). The ratio, $\frac{\hat{\sigma}_{i}}{\hat{\sigma}_{j}}$ in (13), scales the variables so as to account for

differences in the units of magnitudes of the variables.

The BVAR model is estimated using Theil's (1971) mixed estimation technique, which involves supplementing the data with prior information on the distribution of the coefficients. For each restriction imposed on the parameter estimated, the number of observations and degrees of freedom are increased by one in an artificial way. Therefore, the loss of degrees of freedom associated with the unrestricted VAR is not a concern in the BVAR.

4.3.2 DSGE vs. VARs The BVAR model is estimated in levels ${ }^{12}$ with four lags for the period of 1970Q1 to 2000Q4. Consumption, investment and GNP are seasonally adjusted in order to address the fact that, as pointed out by Hamilton (1994:362), the Minnesota prior is not well suited for seasonal data. All variables except for the interest rate are measured in logarithms. We then perform the one-to-eight-period-ahead forecasts for the period of 2001Q1 to 2005Q4. Following Dua et al. (1999), the overall tightness parameter (w) is set equal to 0.1 and 0.2, 1 and 2 for the harmonic lag decay parameter id). Moreover, as in Dua and Ray (1995), we also report the results for a combination of $w=0.3$ and $w=0.5$ -

Tables 3 to 7 summarize the MAPEs of DSGE model and the VARs. In general, for all the five variables the DSGE model performs the worst. This is not a surprising result since the DSGE model is based on only two state variables, the previous capital stock and the productivity shock. The model is, thus, not rich enough to capture most of the movements

${ }^{12}$ Sims et al. (1990) indicate that with the Bayesian approach entirely based on the likelihood function, the associated inference does not need to take special account of non-stationarity, since the likelihood function has the same Gaussian shape regardless of the presence of non-stationarity. 
Table 4. MAPE(2001:1-2005:4): Final consumption expenditure by households in logs

\begin{tabular}{|c|c|c|c|c|c|c|c|}
\hline \multirow[t]{2}{*}{$\overline{\mathrm{QA}}$} & \multirow[t]{2}{*}{ VAR } & \multirow[t]{2}{*}{ DSGE } & \multicolumn{5}{|l|}{ BVARs } \\
\hline & & & $(w=0.3, d=0.5)$ & $(\mathrm{w}=0.2, \mathrm{~d}=1)$ & $(\mathrm{w}=0.2, \mathrm{~d}=2)$ & $(\mathrm{w}=0.1, \mathrm{~d}=1)$ & $(\mathrm{w}=0.1, \mathrm{~d}=2)$ \\
\hline 1 & 0.0035 & 5.0167 & 0.0035 & 0.0034 & 0.0034 & 0.0033 & 0.0030 \\
\hline 2 & 0.0058 & 5.1038 & 0.0058 & 0.0058 & 0.0061 & 0.0059 & 0.0059 \\
\hline 3 & 0.0080 & 5.1879 & 0.0080 & 0.0081 & 0.0087 & 0.0083 & 0.0085 \\
\hline 4 & 0.0094 & 5.2687 & 0.0094 & 0.0096 & 0.0105 & 0.0099 & 0.0103 \\
\hline 5 & 0.0122 & 5.3435 & 0.0122 & 0.0124 & 0.0134 & 0.0128 & 0.0132 \\
\hline 6 & 0.0148 & 5.4093 & 0.0148 & 0.0150 & 0.0160 & 0.0153 & 0.0156 \\
\hline 7 & 0.0176 & 5.4715 & 0.0176 & 0.0178 & 0.0188 & 0.0182 & 0.0184 \\
\hline 8 & 0.0209 & 5.5248 & 0.0209 & 0.0211 & 0.0222 & 0.0215 & 0.0218 \\
\hline AVE & 0.0115 & 5.2908 & 0.0115 & 0.0117 & 0.0124 & 0.0119 & 0.0121 \\
\hline
\end{tabular}

MAPE: mean absolute percentage error; QA: quarter ahead.

Table 5. MAPE(2001:1-2005:4): Investment expenditure in logs

\begin{tabular}{|c|c|c|c|c|c|c|c|}
\hline \multirow[t]{2}{*}{$\overline{\mathrm{QA}}$} & \multirow[t]{2}{*}{ VAR } & \multirow[t]{2}{*}{ DSGE } & \multicolumn{5}{|l|}{ BVARs } \\
\hline & & & $(w=0.3, d=0.5)$ & $(\mathrm{w}=0.2, \mathrm{~d}=1)$ & $(\mathrm{w}=0.2, \mathrm{~d}=2)$ & $(\mathrm{w}=0.1, \mathrm{~d}=1)$ & $(w=0.1, d=2)$ \\
\hline 1 & 0.0376 & 31.6635 & 0.0375 & 0.0374 & 0.0382 & 0.0369 & 0.0370 \\
\hline 2 & 0.0470 & 31.0647 & 0.0471 & 0.0479 & 0.0524 & 0.0496 & 0.0540 \\
\hline 3 & 0.0442 & 30.5257 & 0.0444 & 0.0458 & 0.0532 & 0.0486 & 0.0546 \\
\hline 4 & 0.0464 & 30.0584 & 0.0467 & 0.0485 & 0.0586 & 0.0525 & 0.0620 \\
\hline 5 & 0.0479 & 29.5514 & 0.0482 & 0.0501 & 0.0599 & 0.0538 & 0.0620 \\
\hline 6 & 0.0769 & 28.9947 & 0.0772 & 0.0791 & 0.0893 & 0.0830 & 0.0919 \\
\hline 7 & 0.0569 & 28.4545 & 0.0572 & 0.0595 & 0.0707 & 0.0639 & 0.0728 \\
\hline 8 & 0.0509 & 27.9088 & 0.0513 & 0.0537 & 0.0655 & 0.0584 & 0.0679 \\
\hline AVE & 0.0510 & 29.7777 & 0.0512 & 0.0527 & 0.0610 & 0.0558 & 0.0628 \\
\hline
\end{tabular}

MAPE: mean absolute percentage error; QA: quarter ahead.

Table 6. MAPE(2001:1-2005:4): Employment in logs

\begin{tabular}{|c|c|c|c|c|c|c|c|}
\hline \multirow[t]{2}{*}{$\mathrm{QA}$} & \multirow[t]{2}{*}{ VAR } & \multirow[t]{2}{*}{ DSGE } & \multicolumn{5}{|l|}{ BVARs } \\
\hline & & & $(\mathrm{w}=0.3, \mathrm{~d}=0.5)$ & $(\mathrm{w}=0.2, \mathrm{~d}=1)$ & $(\mathrm{w}=0.2, \mathrm{~d}=2)$ & $(\mathrm{w}=0.1, \mathrm{~d}=1)$ & $(\mathrm{w}=0.1, \mathrm{~d}=2)$ \\
\hline 1 & 0.0133 & 38.9136 & 0.0134 & 0.0138 & 0.0156 & 0.0144 & 0.0167 \\
\hline 2 & 0.0085 & 37.8742 & 0.0085 & 0.0091 & 0.0130 & 0.0102 & 0.0155 \\
\hline 3 & 0.0076 & 36.9046 & 0.0074 & 0.0060 & 0.0036 & 0.0027 & 0.0100 \\
\hline 4 & 0.0197 & 35.9728 & 0.0195 & 0.0198 & 0.0087 & 0.0155 & 0.0015 \\
\hline 5 & 0.0243 & 34.9687 & 0.0241 & 0.0224 & 0.0108 & 0.0185 & 0.0024 \\
\hline 6 & 0.0487 & 33.8304 & 0.0484 & 0.0467 & 0.0347 & 0.0429 & 0.0256 \\
\hline 7 & 0.0912 & 32.7531 & 0.0909 & 0.0886 & 0.0737 & 0.0836 & 0.0629 \\
\hline 8 & 0.1269 & 31.6181 & 0.1265 & 0.0124 & 0.1078 & 0.1188 & 0.0957 \\
\hline AVE & 0.0425 & 35.3545 & 0.0423 & 0.0273 & 0.0335 & 0.0384 & 0.0288 \\
\hline
\end{tabular}

MAPE: mean absolute percentage error; QA: quarter ahead.

of the real data. In addition, theoretically speaking, the methodology applied in this paper, involving calibration and forecasting based on simulated data, is not a preferable option in terms of forecasting. Ideally, these models need to be estimated using the real data.

Regarding the forecasting performances of the VARs, the BVARs outperform the unrestricted VARs in terms of the average MAPEs. It is only in the case of consumption that the unrestricted VAR does as well as a BVAR with the most loose prior ( $w=0.3, d=0.5$ ). Moreover, our result suggests that a BVAR with a relatively loose prior produces smaller out-of-sample forecast errors. For consumption and investment, a BVAR with the most loose prior ( $w=0.3, d=0.5$ ) performs the best, whereas for employment and the short term interest rate, a BVAR with the second most loose prior $(w=0.2, d=1)$ produces the best predictions. The only exception is GNP, for which a BVAR with relatively tighter prior ( $w=$ $0.1, d=1$ ) generates the best forecasts. 
Table 7. MAPE(2001:1-2005:4): 91 days treasury bill rate

\begin{tabular}{|c|c|c|c|c|c|c|c|}
\hline \multirow[t]{2}{*}{$\overline{\mathrm{QA}}$} & \multirow[t]{2}{*}{ VAR } & \multirow[t]{2}{*}{ DSGE } & \multicolumn{5}{|l|}{ BVARs } \\
\hline & & & $(\mathrm{w}=0.3, \mathrm{~d}=0.5)$ & $(\mathrm{w}=0.2, \mathrm{~d}=1)$ & $(\mathrm{w}=0.2, \mathrm{~d}=2)$ & $(\mathrm{w}=0.1, \mathrm{~d}=1)$ & $(\mathrm{w}=0.1, \mathrm{~d}=2)$ \\
\hline 1 & 0.0514 & 44.3911 & 0.0509 & 0.0491 & 0.0309 & 0.0409 & 0.0089 \\
\hline 2 & 0.1254 & 46.1530 & 0.1241 & 0.1168 & 0.0542 & 0.0923 & 0.0010 \\
\hline 3 & 0.2741 & 46.9272 & 0.2787 & 0.3073 & 0.4604 & 0.3721 & 0.5488 \\
\hline 4 & 0.6043 & 46.0619 & 0.6090 & 0.0640 & 0.8215 & 0.7139 & 0.9226 \\
\hline 5 & 0.2955 & 47.3252 & 0.3013 & 0.3388 & 0.5462 & 0.4234 & 0.6238 \\
\hline 6 & 0.3114 & 47.3953 & 0.3056 & 0.2675 & 0.0590 & 0.1831 & 0.0449 \\
\hline 7 & 0.4562 & 48.6340 & 0.4499 & 0.4083 & 0.1846 & 0.3186 & 0.0761 \\
\hline 8 & 0.6259 & 50.4094 & 0.6199 & 0.5789 & 0.3532 & 0.4904 & 0.2438 \\
\hline AVE & 0.3430 & 47.1621 & 0.3424 & 0.2663 & 0.3137 & 0.3293 & 0.3087 \\
\hline
\end{tabular}

MAPE: mean absolute percentage error; QA: quarter ahead.

In short, the BVAR model performs quite well in forecasting compared to the calibrated small-scale DSGE model and the unrestricted VAR model. Furthermore, our finding is the same that of Dua and Ray (1995), that is, a BVAR model with a relatively loose prior generally produces more accurate forecasts.

\section{CONCLUSION}

This paper is the first attempt in using a DSGE model for forecasting the South African economy. However, compared to the VARs and the BVARs, the DSGE model produces large out-of-sample forecast errors. Moreover, we find that a BVAR model with a relatively loose prior generally produces more accurate forecasts. But one must realize that there are some inherent problems with the BVAR models, which the forecaster should keep in mind: Firstly, the forecast accuracy depends critically on the specification of the prior, and secondly, the selection of the prior based on some objective function for the out-of-sample forecasts may not be "optimal" for the time period beyond the period chosen to produce the out-of-sample forecasts. Moreover, the choice of the variables, to be forecasted, using the BVAR models can also affect the tightness, and hence, the optimal prior. In a recent study, Gupta and Sichei (2006), while trying to forecast consumption, investment, GDP, CPI and short- and long-term interest rates for the South African economy, over the same period as in this study, finds the tightest prior to be optimal.

Finally, some areas of future research that can be identified are as follows. As indicated by Rotemberg and Woodford (1995), output is unforecastable with only one state variable. The small-scale DSGE model, developed in this paper, should thus be extended to a more elaborate model that includes a wider set of state variables. In addition, others have found the estimated DSGE models to empirically outperform other econometric models in terms of forecasting inter alia, Christiano et al., 2003, Smets and Wouters, 2004); hence, an estimated version of the current DSGE model should be developed for forecasting the South African economy.

\section{APPENDIX}

\section{A. The log-linearized DSGE model}

This section presents the log-linearized DSGE model. The principle of log-linearization is to replace all equations by Taylor approximation around the steady state, which are linear functions in the log-deviations of the variables (Uhlig, 1995:4). Suppose $X_{t}$ be the vector of variables, $\bar{X}$ their steady state, and $x_{t}$ the vector of log-deviations: 
$x_{t}=\log X_{t}-\log \bar{X}$

in other words, $x_{t}$ denote the percentage deviation from their steady state levels. (14) can be written alternatively:

$X_{t}=\bar{X} e^{x_{t}} \approx \bar{X}\left(1+x_{t}\right)$

In order to derive the log-linearized DSGE model, we need to use (15) to rewrite all the equations of the model and then take logarithms. ${ }^{13}$ The complete model economy:

$Y_{t}=C_{t}+I_{t}$

$Y_{t}=Z_{f} K_{t-1}^{\rho} N_{t}^{1-\rho}$

$K_{t}=(1-\delta) K_{t-1}+I_{t}$

$1=\beta E_{t}\left[\left(\frac{C_{t}}{C_{t+1}}\right)^{\eta} R_{t+1}\right]$

$A=C_{t}^{-\eta}(1-\rho) \frac{Y_{t}}{N_{t}}$

$R_{t}=\rho \frac{Y_{t}}{K_{t-1}}+(1-\delta)$

$\log Z_{t}=(1-\psi) \log \bar{Z}+\psi \log Z_{t-1}+\varepsilon_{t}, \quad \varepsilon_{t} \sim$ i.i.d. $\left(0, \sigma^{2}\right)$

In steady state, we have:

$\bar{Y}=\bar{C}+\bar{I}$

$\bar{Y}=\bar{Z} \bar{K}^{\rho} \bar{N}^{1-\rho}$

$\bar{K}=\left(\frac{\rho \bar{Z}}{\bar{R}-1+\delta}\right)^{\frac{1}{1-\rho}} \bar{N}$

$\bar{I}=\delta \bar{K}$

$A=\frac{1}{\bar{N}}(1-\rho) \frac{\bar{Y}}{\bar{C}^{\eta}}$

${ }^{13}$ For details of log-linearization, see Uhfig (1995). 
$\bar{R}=\frac{1}{\beta}$

The log-linearized equations:

$$
\begin{aligned}
& \bar{Y} y_{t}=\bar{C} c_{t}+\bar{I} i_{t} \\
& y_{t}=z_{t}+\rho k_{t-1}+(1-\rho) n_{t} \\
& \bar{K} k_{t}=\overline{I_{t}}+(1-\delta) \bar{K} k_{t-1} \\
& 0=E_{t}\left[\eta\left(c_{t}-c_{t+1}\right)+r_{t+1}\right] \\
& 0=-\eta c_{t}+y_{t}-n_{t} \\
& \bar{R} r_{t}=\rho \frac{\bar{Y}}{\bar{K}}\left(y_{t}-k_{t-1}\right) \\
& z_{t}=\psi z_{t-1}+\varepsilon_{t}, \quad \varepsilon_{t} \sim \text { i.i.d. }\left(0, \sigma^{2}\right)
\end{aligned}
$$

\section{B. The recursive law of motion}

The principle of undetermined coefficients method is to write all variables as linear functions of a vector of endogenous variables $x_{t-1}$ and exogenous variables $z_{t}$. These variables are also called predetermined variables in the sense that they cannot be changed at date $t$ (Uhlig, 1995). In our simple real business cycle model, the endogenous variable is capital, $k_{t-1}$, and exogenous variable is the productivity shock, $z_{t}$. We further define a list of other endogenous variables $y_{t}$, which includes output $Y$, consumption $C$, investment $I$, employment $N$, and the short term interest rate $R$. The equilibrium relationships between vectors $x_{t-1}, y_{t}$, and $z_{t}$ are:

$$
\begin{aligned}
& 0=A x_{t}+B x_{t-1}+C y_{t}+D z_{t} \\
& 0=E\left[F x_{t+1}+G x_{t}+H x_{t-1}+J y_{t+1}+K y_{t}+L z_{t+1}+M z_{t}\right] \\
& z_{t}=N z_{t-1}+\varepsilon_{t}, \quad \varepsilon_{t} \sim \text { i.i.d. }\left(0, \sigma^{2}\right)
\end{aligned}
$$

The recursive law of motion is derived using Uhlig's MATLAB program: ${ }^{14}$

$$
y_{t}=P x_{t-1}+Q z_{t}
$$

where $y_{t}$ here is a vector of all endogenous variables in log-deviations:

\footnotetext{
${ }^{14}$ See Uhlig (1995) for details of solving recursive stochastic linear systems with the method of undetermined coefficients.
} 


\section{REFERENCES}

BACKUS, D. K., PATRICK, J. and KYDLAND, F. E. (1995). "International business cycles: theory and evidence", In Cooley, T. F. ed., Frontiers in business cycle research. Princeton: Princeton University Press.

CHRISTLANO, L. J. and EICHENBAUM, M. (1992). "Current real-business-cycle theories and aggregate labor-market fluctations", The American Economic Review, 82(3): 430-450.

, EICHENBAUM, M. and EVANS, C. (2003). "Nominal rigidities and the dynamic effects of a shock to monetary policy", Journal of Political Economy, forthcoming.

COOLEY, T. F. and LEROY, S. F. (1985). "Atheoretical macroeconometrics: A Critique", Journal of Monetary Economics, 16: 283-308.

— and PRESCOTT, E. C. (1995). "Economic growth and business cycle", In Cooley, T. F. ed., Frontiers of business cycle research. Princeton: Princeton University Press.

DOAN, T., LITTERMAN, R. B. and SMIS, C. (1984). "Forecasting and conditional projection using realistic prior distributions", Econometric Reviews, 3: 1-144.

DUA, P. and RAY, S. C. (1995). "A BVAR model for the Connecticut Economy", Journal of Forecasting, 14: 167-180. , MILLER, S. M. and SMYTH, D. J. (1999). "Using leading indicators to forecast U.S. home sales in a Bayesian vector autoregression framework", Journal of Real Estate Finance and Economics, 18: 191-205.

GUPTA, R. and SICHEI, M. M. (2006). "A BVAR Model for the South African Economy", South African Journal of Economics, 74(3): 391-409.

HANSEN, G. D. (1985). "Indivisible labor and the business cycle”, Journal of Monetary Economics, 16: 309-327. $281-308$. and SARGENT, T. J. (1988). "Straight time and overtime in equilibrium", Journal of Monetary Economics, 21:

- (1993). “Did technology shocks cause the 1990-1991 recession?” The Economic Review, 83(2): 280-286.

HAMILTON, J. D. (1994). “Time series analysis", 2nd Edition. Princeton: Princeton University Press.

INGRAM, B. F. and WHITEMAN, C. H. (1994). "Supplanting the 'minnesota' prior: forecasting macroeconomic time series using real business cycle model priors", Journal of Monetary Economics, 34(3): 497-510.

KING, R. G., PlOSSER, C. I. and REBELO, S. T. (1988). "Production, growth and business cycles I. The basic Neocalssical model", Journal of Monetary Economics, 21: 195-232.

KYDLAND, F. E. and PRESCOTT, E. C. (1982). "Time to build and aggregate fluctuations", Econometrica, 50(6): $1345-1370$.

LITTERMAN, R. B., (1981). “A Bayesian procedure for forecasting with vector autoregressions”, Working Paper, Federal Reserve Bank of Minneapolis.

- (1986). "Forecasting with Bayesian vector autoregressions - five years of experience", Journal of Business and Statistics, 4(1): 25-38.

LUCAS, R. E. Jr., (1976). "Econometric policy evaluation: A critique", Carnegie Rochester Conference Series on Public Policy, 1: $19-46$.

ROTEMBERG, J. and WOODFORD, M. (1995). “Dynamic general equilibrium models with imperfectly competitive product markets", In Cooley, T. F. ed., Frontiers in business cycle research. Princeton: Princeton University Press.

SIMS, C. A., (1980). "Macroeconomics and reality", Econometrica, 48(January): 1-48.

-, STOCK, J. H. and WATSON, M. W. (1990). "Inference in linear time series models with some unit roots", Econometrica, 58: 113-144.

SMETS, F. and WOUTERS, R. (2003a). "An estimated dynamic stochastic general equilibrium model of the euro area", Journal of the European Economic Association, 1(5): 1123-1175.

- (2003b). "Shocks and frictions in US business cycle: a Bayesian DSGE approach", Mimeo, European Central Banks.

(2004). "Forecasting with a Bayesian DSGE model: an appication to the Euro area", European Central Banks, Working Paper, No. 389.

SMIT, B. W. and BURROWS, L. R. (2002). "Estimating potential output and output gaps for the South African economy", Stellenbosch Economic Working Papers, No. 5.

SOLOW, R. M., (1957). "Technical change and the aggregate production function", The Review of Economics and Statistics, 39(3): $312-320$. 
THEIL, H., (1971). Principles of econometrics. New York: John Wiley.

UHLIG, H., (1995). "A toolkit for analyzing nonlinear dynamic stochastic models easily", Discussion Paper 101. Institute for Empirical Macroeconomics, Federal Reserve Bank of Minneapolis.

WHITLEY, J. D. (1994). "A course in macroeconomic modelling and forecasting", Herffordshire: Harvester Wheatsheaf. ZELLNER, A. (1979). "Statistical analysis of econometric models", Journal of the American Statistical Association, 74: 628-643.

and PALM, F. (1974). "Time series analysis and simultaneous equation econometric models", Journal of Econometrics, 2: 17-54.

ZIMMERMANN, C. (2001). "Forecasting with real business cycle models", Center for Research on Economic Fluctuations and Employment, Working paper, No. 131. 